\title{
Effect of socioeconomic factors on malnutrition among children in Pakistan
}

\author{
Dilshad Ahmad ${ }^{1 *}$ (D), Muhammad Afzal ${ }^{2}$ and Aisha Imtiaz ${ }^{1}$
}

\begin{abstract}
Background: In the current era, malnutrition among children considers main reason of morbidity and mortality in the world scenario while more specifically in developing countries. Malnutrition in children severely affects their physical growth and academic achievements. This study aimed to find out the effect of socioeconomic factors on malnutrition, children aged under 5 years in Multan district of Punjab province, Pakistan. The study used the data of 2497 children, obtained from Multiple Integrated Cluster Survey 2018 and employed Binary logistic regression approach for empirical estimation the effects of socioeconomic factors on malnutrition among children.

Results: Empirical estimates of the study specified the prevalence of higher frequency of stunting (18.58), wasting (28.43) and underweight (19.54) among children particularly in rural areas of the study district Multan. Stunting status was significantly associated with children of some month $(\mathrm{OR}=1.247, \mathrm{Cl} 95 \% 0.543-1.546)$, family size $(\mathrm{OR}=0.589$, Cl 95\% 0.431-3.715), maternal education ( $O R=1.432$, Cl 95\% 0.528-1.972), wealth quintile (OR=2.174, $\mathrm{Cl} 95 \%$ 1.234-3.376) and sanitation facility $(\mathrm{OR}=0.789, \mathrm{Cl} 95 \% 0.627-1.987)$. Wasting status was mostly correlated with male children $(\mathrm{OR}=1.208, \mathrm{Cl} 95 \%$ 0.769-1.352), children of urban areas ( $\mathrm{OR}=0.594, \mathrm{Cl} 95 \%$ 0.476-1.987) and food shortage $(\mathrm{OR}=1.367, \mathrm{Cl} 95 \%$ 0.782-2.543). Underweight status was close relationship with male gender $(\mathrm{OR}=1.213, \mathrm{Cl} 95 \%$ $0.821-2.897)$, incomplete immunization $(\mathrm{OR}=1.342, \mathrm{Cl} 95 \% 1.041-2.658)$ and treated water access $(\mathrm{OR}=0.689, \mathrm{Cl}$ $95 \%$ 0.542-2.743).

Conclusion: In this study, prevalence of higher-level malnutrition was estimated due to lower socioeconomic status among major population in the community specifically in rural areas. The government needs to enhance economic opportunities, promote healthcare education, increase nutritional access and generate improving personal hygiene habits through appropriate economic, political and social policy measures. The outcome of these policies will enhance individual economic resources; ensure nutritional safety, increasing maternal schooling and helpful for improving child health.
\end{abstract}

Keywords: Children, Malnutrition, Stunting, Wasting, Underweight

JEL Classification: 110, I12, 115, 012

\section{Introduction}

Malnutrition signifies with disproportion of energy and nutrients in physical status among children and adults [91]. Malnutrition elimination in its all forms indicated 2nd Sustainable Development Goals (SDGs) of United

\footnotetext{
*Correspondence: dilshad@ciitvehari.edu.pk

${ }^{1}$ Department of Management Sciences, COMSATS University Islamabad,

Vehari Campus, Islamabad, Pakistan

Full list of author information is available at the end of the article
}

Nations [85] as ultimate purpose is all children free from malnutrition issue [89]. Under nutrition, prevalence (stunting, wasting and underweight) generates more chances of disease and death among children [83]. Micronutrient-related malnutrition is deficiency of vitamins and iron [90]. Over nutrition (overweight and obesity) indicates risk factors of non-communicable diseases (NCDs). Under nutrition, micronutrient-related malnutrition and over nutrition are all forms of malnutrition [71, 91]. Child malnutrition indicates as suffering in one 
or more than one forms as underweight, stunting and wasting [89]. Stunting indicated as short height for age, underweight as low weight for age while low weight as compared to height identified as wasting [90].

Community level socioeconomic factors play crucial role in prevalence and incidence of malnutrition [20,54]. Gender inequality, education, poverty, sanitation and safe water access are some considerable socioeconomic factors to determine health outcomes in many developing and underdeveloped countries [9]. There is significant systematic literature sated with substantiation of relationship between malnutrition, low maternal schooling and poverty $[1,53,70]$. In the current scenario of advancement, malnutrition still emerging severe community health and for long time recognized as consequent of poverty [84]. Children from low socioeconomic household status are 2.5 times more vulnerable of malnutrition rather than middle or upper socioeconomic household status [46]. Higher vulnerability of food insecurity is associated with households' lower socioeconomic status because nutritious food affordability closely associated with purchasing power [9]. Households facing limitations in social and economic development are most probably face issues in physical growth [10] due to consumption of poor food, illness scenario, sanitation insufficiency, pitiable hygienic practice and inadequate safe water access [82]. Higher maternal schooling can reduce child malnutrition through enhancing awareness regarding sanitation practices, healthy practices and optimal resources allocation in children favor [73, 86]. Paternal schooling significantly influences in provision of family adequate nutrition, shelter, sanitation due to sound income and appropriate use of resources [55]. Socioeconomic development and malnutrition reduction rate in children be able to make available significant insight for get better living status in most developing countries [92].

In the world scenario, almost 149 million as $21.9 \%$ children under five are stunted, 49.5 millions as $7.3 \%$ wasted while 40.1 millions $5.9 \%$ overweight, indicated the slower tendency of decreasing in stunting and wasting with increasing tendency in overweight regarding 2018 as compared to 2000 era [83, 88, 90]. In all forms of malnutrition, Asian region share more severe scenario regarding stunting 81.7 million (55\%), wasting 33.8 million (68.28\%) and 18.8 million (47\%) of overweight of the world total malnutrition status [90]. In Asian region according to classification of United Nations, Southern Asian region countries share higher frequency of stunting 57.9 million (71\%), 25.3 million (75\%) wasting and 5.5 million $(30 \%)$ overweight in the region and showing the higher severely of malnutrition in this region [88].

The aspect of malnutrition has discussed in many significant studies in Pakistan regarding provincial basis
(Punjab, Sindh, Khyber Pakhtunkhwa, Balochistan), locality scenario (rural/urban), various types (community base/hospital base), gender status (boys/girls), regarding participation (children/mother and child/ guardian/mother and caretaker) and different age levels $(<5$ years/5-10 years/5-12 years) with estimating different methodologies and data sets. The study of [2] focused the Quetta city of Balochistan, while the studies of [12, 21, 42, 45, 47, 59, 68, 72, 93] discussed Sindh province rural and urban areas to addressing malnutrition issue in the province. The studies of $[3,5,33,44,65$, 81] spotlighted different rural and urban areas of Khyber Pakhtunkhwa province, and the research work of $[52,58]$ focused the Islamabad urban areas for highlighting the malnutrition scenario in these areas.

In Pakistan, almost half of children less than five are stunted and one out of ten children indulged in wasting (State Bank of Pakistan (SBP), 2019) [75]. Pakistan is also categorized among those seven countries of the world accounted two-thirds of the world under nourished population as China, Bangladesh, Congo, Indonesia, India and Ethiopia [23, 75]. In the world scenario, Pakistan is unexpectedly higher malnutrition affecting county ranked as 77 out of 113 countries; it is also categorized highest stunted country in the region Southern Asian Countries (SAC) while having among higher wasting scenario among southern countries region [83, 88, 90]. Pakistan are performing slow and are still experiencing severe malnutrition issue among children less than 5-year prevalence of stunting $40.2 \%$, wasting $17.7 \%$, underweight $28.9 \%$ and overweight $9.5 \%$, relatively higher among developing countries [83]. In Pakistan, rural community has higher frequency of stunting (43.2\%), wasting (18.6\%) and underweight (31.6\%) rather than urban locality stunting (34.8\%), wasting (16.2\%) and underweight (24\%); in gender base scenario, boys are more stunted, wasted, underweight and overweight rather than girls [82]. In province wise scenario, higher prevalence of stunting and overweight is estimated in Balochistan and higher tendency in wasting and underweight in Sindh province rather than Punjab and Khyber Pakhtunkhwa [82].

In the scenario of Punjab province, there are only limited studies of $[7,8,13,50,57,58,66]$ significantly focused Eastern and Central Punjab and only the single study of [43] focused data of school children of 5-14 years from rural area of Bahawalpur to focusing southern Punjab region of Punjab province Pakistan. This region is absolutely neglected to highlighting malnutrition standing among children under 5 years in this area so to addressing such gap this study tried focus some aspects. Firstly, this study focused malnutrition status among children under 5 years in this region which not properly highlighted in southern Punjab area, secondly 
this study focused both urban and rural areas and both gender in the study no research work in such scenario in this locality, and thirdly this study selected Multan city the biggest city of southern Punjab and 8th major city of Pakistan [29]. Lastly, Multan has the highest frequency of stunting, wasting and underweight in Punjab rather than other populated cities of Punjab such as Lahore, Faisalabad, Rawalpindi and Gujranwala [30]. The main objective related to this specific study is to recognize the effect of socioeconomic factors on malnutrition among children below 5 years in southern Punjab of Pakistan. This study is categorized into six sections as introduction of the study explained in the first section, theoretical frame work highlighted in section two, while section three indicated the data and methodology of the study. In section four, results of the study are elaborated as discussion of study highlighted in section five while conclusion given in the last section of the study.

\section{Theoretical framework}

This theory has its background in microeconomics household production models of Becker's [14] indicating as families trade in goods and time in mass production of products either utilize at home or purchase from the market. Grossman [32] expanded the theory 'Demand for Health', and it was further improved by a number of economists like $[15,17,76]$. Becker [14] has focused household factors of nutrition as 'nutrition production function' indicates the status of child's nutrition as health 'inputs' set. Child's nutritional position reveals the joint properties of many features, together with birth order, health, nutrient intake and communication features directed by preferences of parental as follow in child's nutritional production function.

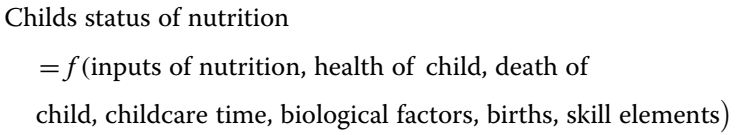

'Theory of Justice' presented by John Rawls' [38] suggests widespread right to use is named 'social primary goods' (similar to liberties, chances, self-confidence, etc.) intended for every one of persons in the community with most important consequence of development in human capital, human rights and adequate health and nutritional access to children [64]. Malnutrition known as component of a vicious cycle comprises three elements disease; malnutrition and poverty are associated in such a means to everyone supply to the existence of the others $[61,67]$. There are different methods for the measurement of under nutrition as explained in Fig. 1. Factors why a person can be malnourished are enumerated in the left mainly column of Fig. 1 . The column two or four indicates different measures of under nutrition. Column two illustrates one is to estimation expenditure directly or energy intake, second column highlights anthropometric measurements, and third column describes further indications that in a roundabout way reveals an insufficient

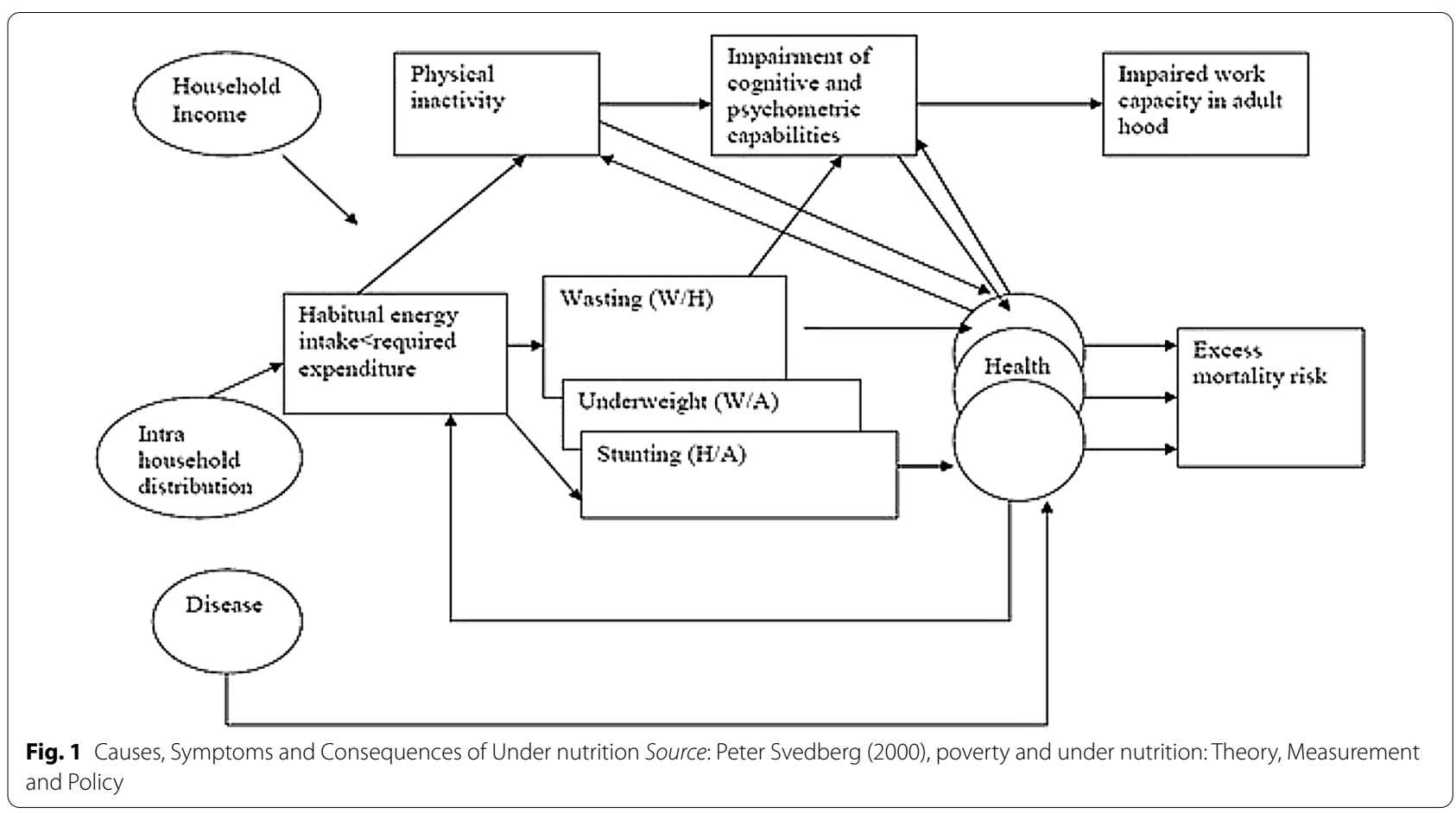


energy balance. Column four identifies quantifiable signs of negative costs of a disproportionately low down energy balance. Figure illustrated reveals the basic associations in the economics-nutrition-health composite [77].

\section{Data and methodology}

This study used the data of Multiple Indicator Cluster Survey (MICS) 2018 [31] for empirical analysis. According to availability of MICS survey data, overall numbers of children under 5 years of age from Multan were 2521 and after removing all missing values, almost 2497 children's data were used in final analysis. Stunting (height for age), wasting (weight for height) and underweight (weight for age) were three major anthropometric indicators [90] used to measure malnutrition association with response variables. The significant socioeconomic factors linked by child malnutrition used in this study were age, gender, mother education (none/pre-school, primary, middle, secondary and higher), family income (lowest, secondary, middle, higher and highest), family size, area (rural, urban), food access, treated water, immunization status and sanitation facility [83]. There are some significant reasons for the selection of study area, firstly Pakistan was selected for the study due to relatively higher prevalence of malnutrition among Southern Asian developing countries and slower malnutrition reducing scenario among these countries $[23,90]$, secondly Punjab province among four provinces was chosen for the study the basis of most populated province and sharing $53 \%$ population of the country [30], thirdly in Punjab province, southern Punjab region was chosen for the study owing to higher occurrence of stunting, wasting, overweight and underweight from the rest of the region of Punjab province [31], and lastly Multan district was selected for the study as most populated main city of southern Punjab and $8^{\text {th }}$ major city of Pakistan as indicated in Fig. 2 [29].

Child's height (height for age), weight (weight for height) and weight (weight for age) more than two standard deviations below the median $(-2 \mathrm{SD})$ of WHO indication population then (s) child as considered stunted, wasted and underweight in that order [90]. Estimating the impact of various socioeconomic factors on malnutrition status by considering various dependent variables for stunting, wasting and underweight, three logistic regression models were used. Statistical data were reported as mean, standard deviation and categorical variables reported as $\mathrm{N}$ (percentage).

Ordinary least square (OLS), probit regression model, logit regression model and tobit regression model were most probably used for the empirical estimation of research studies. In the scenario of binary-dependent variable 0 or 1 , ordinary least square (OLS) may not be suitable because the residual (error) would not be distributed normally. Linear probability model violates all

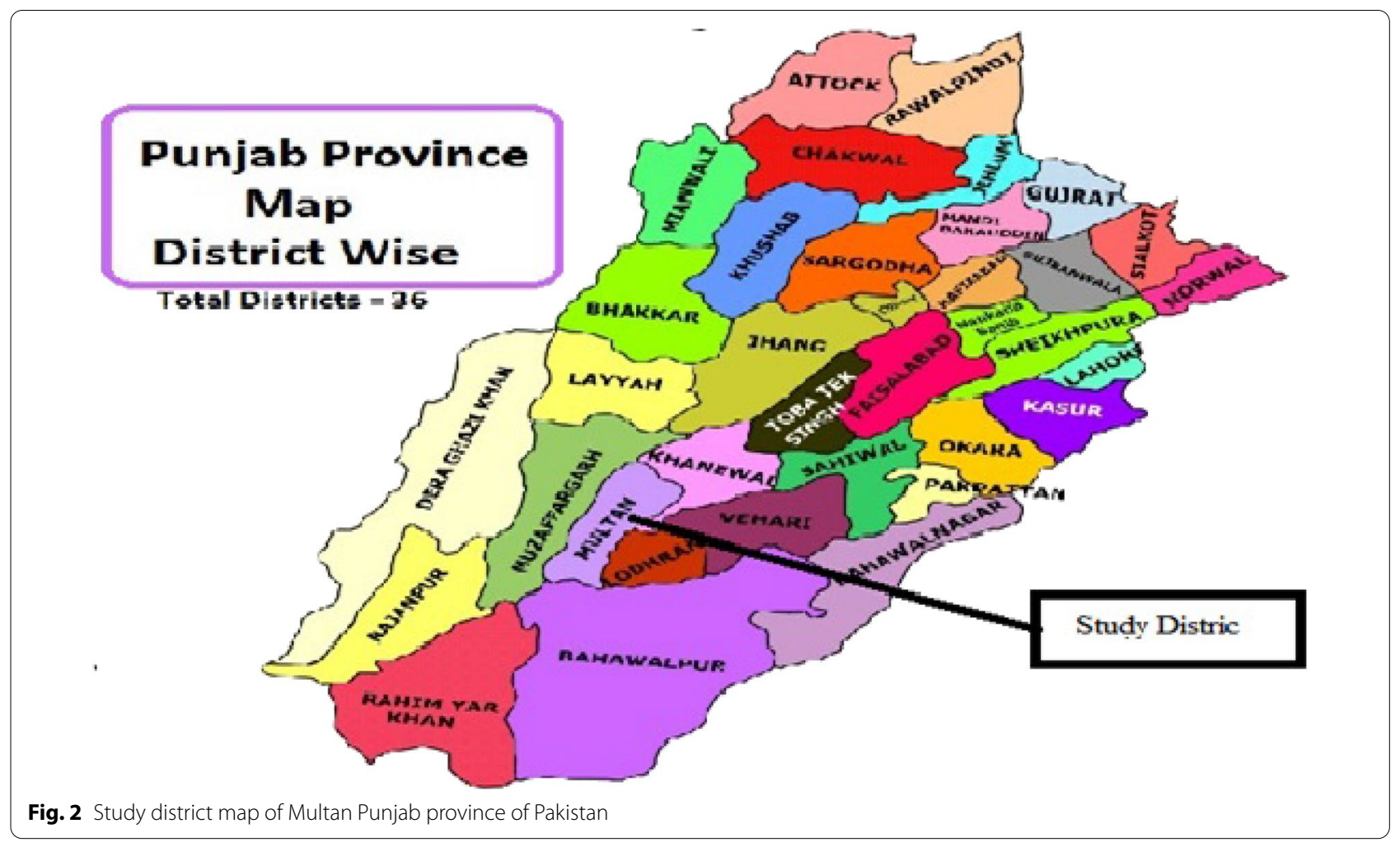


the assumptions on which binary models are based then the logistic regression model more appropriate for estimating regarding the binary-dependent variables [35]. Logistic regression is a statistical method which is widely used in different research areas especially in health sciences when dependent variable is of qualitative nature means variables that are not numerical. Regression with dependent variable having two categories is called binary logistic regression. In this regression, dependent variable is converted into logit function to get maximum likelihood estimation using an iterative technique that returns the 'best explaining values for the population parameters' $[36,39,40]$. The binary logistic regression equation for the model which has to be estimated based on the functional form will be as:

$$
\begin{aligned}
\mathrm{MSC}= & \beta_{0}+\beta_{1} \text { age }+\beta_{2} \text { gender }+\beta_{3} \text { MED }+\beta_{4} \text { family size } \\
& +\beta_{5} \text { area }+\beta_{6} \text { family income }+\beta_{7} \text { food access } \\
& +\beta_{8} \text { immunization status }+\beta_{9} \text { treated water access } \\
& +\beta_{10} \text { sanitation access }+\mu_{i}
\end{aligned}
$$

where $\mathrm{MSC}=$ malnutrition status of children 1 or 0 . Child who has stunted, wasted or underweight or any combination of three is measured as malnutrition. Independent variables are indicated as Age as age of child (in years), Gender as gender status of child (male/female), MED as mother education (in schooling years), FI as family income (various categories), FS as family size, Area as location (rural or urban), food access (yes/no), immunization status (yes/no), treated water access (yes/ no) and sanitation access (yes/no). In this study for statistical analysis of data estimation, SPSS software version 23 has used.

\section{Results}

Socioeconomic variables descriptive statistics of the study are reported in Table 1, and logistic regression model estimated parameters to recognize socioeconomic factors influencing stunting, wasting and underweight of children age $<5$ years presented in Table 2 . In total sample size of 2497 children, 1193 were male and 1304 female children as representing $47.78 \%$ and $52.22 \%$, respectively, with estimated mean value 1.62 and standard deviation of 0.465 . Out of total sample size of 2497 children, 584 (23.39\%) aged of some months, 462 (18.5\%) children aged 1 year, 479 (19.18\%) children aged 2 years, 503 (20.14\%) children as of 3 years, and $469(18.78 \%)$ children were aged 4 years or above while below 5 years. Child age estimated mean value is 1.89 with standard deviation of 1.397 . In total sample of 2497 children, 986 (39.49\%) children were living in household family size of (less than 5) while almost 1321 (54.14\%) children household family size (6-10).

\begin{tabular}{|c|c|c|c|c|}
\hline Characteristics & Number & Percentage & Mean & $\begin{array}{l}\text { Standard } \\
\text { deviation }\end{array}$ \\
\hline Gender & 2497 & & 1.62 & 0.465 \\
\hline Male & 1193 & 47.78 & & \\
\hline Female & 1304 & 52.22 & & \\
\hline Age of child & 2497 & & 1.89 & 1.397 \\
\hline 0 (some month) & 584 & 23.39 & & \\
\hline 1 (in the year) & 462 & 18.5 & & \\
\hline 2 (in the year) & 479 & 19.18 & & \\
\hline 3 (in the year) & 503 & 20.14 & & \\
\hline 4 (in the year) & 469 & 18.78 & & \\
\hline Family size & 2497 & & 1.68 & 0.594 \\
\hline$>5$ & 986 & 39.49 & & \\
\hline $6-10$ & 1321 & 54.14 & & \\
\hline $11-15$ & 181 & 7.25 & & \\
\hline 16 and above & 9 & 0.36 & & \\
\hline Area & 2497 & & 1.47 & 0.471 \\
\hline Urban & 1052 & 42.13 & & \\
\hline Rural & 1445 & 57.87 & & \\
\hline Mother education level & 2497 & & 2.11 & 1.329 \\
\hline Non/pre-school & 1293 & 51.78 & & \\
\hline Primary & 495 & 19.82 & & \\
\hline Middle & 256 & 10.25 & & \\
\hline Secondary & 235 & 9.41 & & \\
\hline Highest & 218 & 8.73 & & \\
\hline Wealth quintile & 2497 & & 2.87 & 1.342 \\
\hline Lowest & 584 & 23.39 & & \\
\hline Secondary & 496 & 19.86 & & \\
\hline Middle & 488 & 19.54 & & \\
\hline Fourth & 544 & 21.79 & & \\
\hline Highest & 385 & 15.42 & & \\
\hline Food access & 2497 & & 2.73 & 1.431 \\
\hline Food shortage & 1870 & 74.89 & & \\
\hline Sufficient food & 627 & 25.11 & & \\
\hline Immunization status & 2497 & & 1.67 & 0.942 \\
\hline Incomplete & 1927 & 77.17 & & \\
\hline Complete & 570 & 22.83 & & \\
\hline Treated water access & 2497 & & 1.43 & 0.874 \\
\hline Yes & 1143 & 45.77 & & \\
\hline No & 1354 & 54.23 & & \\
\hline Sanitation access & 2497 & & 1.89 & 1.327 \\
\hline Yes & 1958 & 78.41 & & \\
\hline No & 539 & 21.59 & & \\
\hline Stunting & 2497 & & 0.97 & 0.389 \\
\hline Yes & 464 & 18.58 & & \\
\hline No & 2033 & 81.42 & & \\
\hline Wasting & 2497 & & 0.81 & 0.492 \\
\hline Yes & 710 & 28.43 & & \\
\hline No & 1787 & 71.57 & & \\
\hline
\end{tabular}
Out of total sample, 181 (7.25\%) children were living
Table 1 Socioeconomic characteristics descriptive statistics of the study 
Table 1 (continued)

\begin{tabular}{lcccl}
\hline Characteristics & Number & Percentage & Mean & $\begin{array}{l}\text { Standard } \\
\text { deviation }\end{array}$ \\
\hline Underweight & 2497 & & 0.74 & 0.368 \\
Yes & 488 & 19.54 & & \\
No & 2009 & 80.46 & & \\
\hline
\end{tabular}

in household family size (11-15) and $9(0.36 \%)$ children with household family size (above 15). Family sizes mean value was reported 1.68 with value of standard deviation of 0.594 . In total sample, $1052(42.13 \%)$ children were inhabited in urban area while 1445 (57.87\%) from rural area of Multan district of Punjab province, Pakistan with mean value of 1.47 and standard deviation 0.471 . Mother education level showed almost 1293 (51.78\%) children's mothers were illiterate while $495(19.82 \%)$ with primary education and $256(10.25 \%)$ as middle education. Out of total sample, 235 (9.41\%) children mother education was secondary schooling and 218 (8.73\%) schooling of higher education with estimated mean value 2.11 and standard deviation of 1.329 .

In sample size of 2497 children, 584 (23.39\%) children were living in the lowest household wealth quintile while $496(19.86 \%)$ children related to secondary wealth quintile and $488(19.54 \%)$ children associated with middle wealth quintile index. Out of total sample, 544 (21.79\%) children were in fourth wealth quintile index and 385 (15.42\%) children in highest household wealth quintile index with mean value of 2.87 and standard deviation 1.342. In food access status in total sample, 1870 (74.89\%) children were facing food shortage while 627 (25.11\%) using adequate food with mean value of 2.73 and standard deviation 1.431. A higher frequency of children 1927 (77.17\%) not completed their immunization of age and only 570 (22.83\%) completed their immunization status with mean of 1.67 and standard deviation 0.942 . A limited number of children 1143(45.77) were access of treated water while 1354 (54.23\%) not use treated water with estimated mean value of 1.43 and standard deviation 0.874 . Out of total sample, 539 (21.59\%) were not using sanitation facility and $1958(78.41 \%)$ access of sanitation as mean of 1.89 and standard deviation 1.327 . In total sample, $18.58 \%$ children stunted, $28.43 \%$ children wasted, and $19.54 \%$ were underweight in study area as indicated in Table 1.

In Table 2, empirical findings of the study elaborated male children were 1.208 and 1.213 time more risk of wasting and underweight rather than female children $(\mathrm{OR}=1.208$, CI $95 \% 0.769-1.352, p$ value $<0.003)$ and $(\mathrm{OR}=1.213$, CI 95\% 0.821-2.897, $p$ value $<0.002)$. Children of some month were 1.247, 1.329 and 1.497 times more stunted, wasted and underweight rather than children aged of 4 years $(\mathrm{OR}=1.247$, CI 95\% $0.543-$ $1.546, p$ value $<0.002),(\mathrm{OR}=1.329$, CI $95 \% 1.068-2.487$, $p$ value 0.001$)$ and $(\mathrm{OR}=1.497, \mathrm{CI} 95 \% 0.761-2.754$, $p$ value 0.003$)$. Children of 1 year were 1.181 and 1.246 times higher prevalence of stunting and wasting rather than 4 year children $(\mathrm{OR}=1.181, \mathrm{CI} 95 \%$ 0.719-1.487, $p$ value 0.003$)$ and $(\mathrm{OR}=1.246, \mathrm{CI} 95 \% 0.683-1.854, p$ value $<0.002$ ). Lower family size $0.589,0.473$ and 0.387 times less risk of stunting, wasting and underweight rather than large family size ( $O R=0.589$, CI $95 \% 0.431-$ $3.715, p$ value $<0.003)$, $(\mathrm{OR}=0.473$, CI $95 \% 0.348-1.249$, $p$ value 0.001$)$ and $(\mathrm{OR}=0.387, \mathrm{CI} 95 \% 0.264-2.327$, $p$ value $<0.002$ ). In urban areas, children were 0.594 times less risk of wasted rather than rural areas children $(\mathrm{OR}=0.594$, CI 95\% 0.476-1.987, $p$ value 0.002). Children of illiterate, primary and middle educated mother were 1.432, 1.274 and 1.127 times more stunted than higher educated mothers children's $(\mathrm{OR}=1.432$, CI 95\% 0.528-1.972, $p$ value 0.012), $(\mathrm{OR}=1.274$, CI 95\% $0.386-2.431, p$ value $<0.003)$ and $(\mathrm{OR}=1.127$, CI $95 \%$ $0.247-2.327, p$ value 0.001$)$. Children belong to lowest wealth quintile family were $2.174,2.243$ and 1.258 times more expected to stunted rather than children's related to highest wealth quintile ( $\mathrm{OR}=2.174$, CI 95\% 1.234 $3.376, p$ value 0.027$),(\mathrm{OR}=2.243$, CI $95 \% 1.261-3.287$, $p$ value $<0.002)$ and $(\mathrm{OR}=1.258$, CI $95 \% 0.831-2.473, p$ value 0.016 ).

Household families facing the status of food shortage their children were 1.874, 1.367 and 1.783 time more risk of stunting, wasting and underweight rather the families sufficient access of food (OR $=1.874$, CI 95\% 0.764 2.851, $p$ value 0.021$),(\mathrm{OR}=1.367$, CI $95 \% 0.782-2.543$, $p$ value 0.004$)$ and $(\mathrm{OR}=1.783$, CI $95 \% 0.857-2.647, p$ value $<0.002)$. Families with incomplete children immunization status their children were 1.387, 1.541 and 1.342 times more occurrence of stunting, wasting and underweight rather the children with complete immunization status $(\mathrm{OR}=1.387$, CI 95\% 1.123-2.431, $p$ value $<0.019)$, $(\mathrm{OR}=1.541, \mathrm{CI} 95 \%$ 0.754-2.687, $p$ value 0.001$)$ and $(\mathrm{OR}=1.342$, CI 95\% 1.041-2.658, $p$ value 0.004$)$. Children with access of treated water were 0.593 and 0.689 times less risk of stunting and underweight rather the children having no access of treated water $(\mathrm{OR}=0.593$, CI $95 \% 0.387-1.965, p$ value 0.031$)$ and $(\mathrm{OR}=0.689$, CI $95 \% 0.542-2.743, p$ value $<0.002$ ). Families with access of sanitation facility their children was 0.789 times less risk of stunting rather children of children no access of sanitation $(\mathrm{OR}=0.789$, CI 95\% 0.627-1.987, $p$ value 0.001$)$.

\section{Discussion}

In developing countries like Pakistan, child malnutrition is emerging as foremost public issues. Inadequate dietary intake, insufficient caring, infectious disease and 
Table 2 Parameters estimates of logistic regression model and factors affecting stunting, wasting and underweight

\begin{tabular}{|c|c|c|c|c|c|c|}
\hline \multirow[t]{2}{*}{ Parameters } & \multicolumn{2}{|l|}{ Stunting } & \multicolumn{2}{|l|}{ Wasting } & \multicolumn{2}{|l|}{ Underweight } \\
\hline & Odd ratio $(95 \% \mathrm{Cl})$ & $p$ value & Odd ratio $(95 \% \mathrm{Cl})$ & $p$ value & Odd ratio $(95 \% \mathrm{Cl})$ & $p$ value \\
\hline \multicolumn{7}{|l|}{ Gender } \\
\hline Male & $1.712(0.684-2.187)$ & 0.279 & $1.208(0.769-1.352)$ & $0.003^{*}$ & $1.213(0.821-2.897)$ & $0.002^{*}$ \\
\hline Female $^{\circledR}$ & 1 & & 1 & & 1 & \\
\hline \multicolumn{7}{|l|}{ Age } \\
\hline 0 (in months) & $1.247(0.543-1.546)$ & $0.002^{* *}$ & $1.329(1.068-2.487)$ & $0.001^{*}$ & $1.497(0.761-2.754)$ & $0.003^{*}$ \\
\hline 1 (year) & $1.181(0.719-1.487)$ & $0.001^{* *}$ & $1.246(0.683-1.854)$ & $0.002^{*}$ & $1.347(0.854-1.987)$ & 0.478 \\
\hline 2 (year) & $1.347(0.687-3.781)$ & 0.529 & $0.467(0.393-1.866)$ & 0.287 & $0.834(0.587-1.673)$ & 0.824 \\
\hline 3 (year) & $1.234(0.768-1.974)$ & 0.481 & $0.687(0.498-1.873)$ & 0.794 & $0.752(0.456-1.239)$ & 0.263 \\
\hline 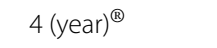 & 1 & & 1 & & 1 & \\
\hline \multicolumn{7}{|l|}{ Family size } \\
\hline $1-5$ & $0.589(0.431-3.715)$ & $0.003^{*}$ & $0.473(0.348-1.249)$ & $0.001^{*}$ & $0.387(0.264-2.327)$ & $0.002^{*}$ \\
\hline $6-10$ & $0.729(0.681-4.289)$ & 0.725 & $0.693(0.378-1.324)$ & 0.864 & $0.448(0.281-2.347)$ & 0.693 \\
\hline $1-15$ & $0.654(0.459-5.781)$ & 0.378 & $0.711(0.529-1.281)$ & 0.679 & $0.376(0.298-4.412)$ & 0.478 \\
\hline $16-20^{\circledR}$ & 1 & & 1 & & 1 & \\
\hline \multicolumn{7}{|l|}{ Area } \\
\hline Urban & $0.871(0.679-1.548)$ & 0.486 & $0.594(0.476-1.987)$ & $0.002^{*}$ & $0.697(0.397-1.473)$ & 0.579 \\
\hline Rural ${ }^{\circledR}$ & 1 & & 1 & & 1 & \\
\hline \multicolumn{7}{|l|}{ Mother education } \\
\hline Pre-school & $1.432(0.528-1.972)$ & $0.012^{* *}$ & $1.576(1.322-2.337)$ & 0.268 & $1.335(1.114-3.482)$ & 0.192 \\
\hline Primary & $1.274(0.379-2.431)$ & $0.003^{*}$ & $1.496(1.237-2.832)$ & 0.371 & $1.389(1.131-2.156)$ & 0.489 \\
\hline Middle & $1.127(0.247-2.327)$ & $0.001^{*}$ & $1.102(0.497-2.568)$ & 0.749 & $0.514(0.161-1.642)$ & 0.261 \\
\hline Secondary & $1.231(0.417-2.247)$ & 0.147 & $0.781(0.348-1.823)$ & 0.647 & $0.526(0.164-1.690)$ & 0.281 \\
\hline Higher $^{\circledR}$ & 1 & & 1 & & 1 & \\
\hline \multicolumn{7}{|l|}{ Wealth quintile } \\
\hline Lowest & $2.174(1.234-3.376)$ & $0.027^{* *}$ & $2.243(1.261-3.287)$ & $0.002^{*}$ & $1.258(0.831-2.473)$ & $0.016^{*}$ \\
\hline Secondary & $1.852(1.288-2.015)$ & 0.471 & $1.603(1.340-2.543)$ & 0.431 & $1.719(0.273-1.941)$ & 0.571 \\
\hline Middle & $1.317(0.426-2.474)$ & 0.787 & $1.450(1.240-3.618)$ & 0.262 & $0.619(0.359-1.764)$ & 0.439 \\
\hline Fourth & $1.143(0.549-2.712)$ & 0.438 & $1.302(1.275-2.051)$ & 0.636 & $0.513(0.289-1.438)$ & 0.213 \\
\hline Higher $^{\circledR}$ & 1 & & 1 & & 1 & \\
\hline \multicolumn{7}{|l|}{ Food access } \\
\hline Food shortage & $1.874(0.764-2.851)$ & $0.021^{* *}$ & $1.367(0.782-2.543)$ & $0.004^{*}$ & $1.783(0.857-2.647)$ & $0.002^{*}$ \\
\hline Sufficient Food ${ }^{\circledR}$ & 1 & & 1 & & 1 & \\
\hline \multicolumn{7}{|c|}{ Immunization status } \\
\hline Incomplete & $1.387(1.123-2.431)$ & $0.019^{* *}$ & $1.541(0.754-2.687)$ & $0.001^{*}$ & $1.342(1.041-2.658)$ & $0.004^{*}$ \\
\hline Complete ${ }^{\circledR}$ & 1 & & 1 & & 1 & \\
\hline \multicolumn{7}{|c|}{ Treated water access } \\
\hline Yes & $0.593(0.387-1.965)$ & $0.031^{* *}$ & $1.243(1.023-2.763)$ & 0.714 & $0.689(0.542-2.743)$ & $0.002^{*}$ \\
\hline $\mathrm{No}^{\circledR}$ & 1 & & 1 & & 1 & \\
\hline \multicolumn{7}{|l|}{ Sanitation access } \\
\hline Yes & $0.789(0.627-1.987)$ & $0.001^{*}$ & $1.479(1.087-2.857)$ & 0.491 & $0.817(0.679-1.572)$ & 0.241 \\
\hline $\mathrm{No}^{\circledR}$ & 1 & & 1 & & 1 & \\
\hline
\end{tabular}

* $10 \%$ level of significance

* $5 \%$ level of significance

*** $1 \%$ level of significance

household level discriminatory food distribution are major causes of children higher vulnerability to malnutrition [26, 80, 87]. Male children were identified higher risk of malnutrition in this study with higher frequency of wasting, stunting and underweight comparative to female children as could partially explained reasoned of as male 
consider more vulnerable due to health inequalities to early childhood diseases and health problems rather than female children [19]. These results are consistent with previous research work of $[4,19,26,41,51,79]$. Children of some months and 1 year were more risk of malnutrition as children of 4 years with frequency of stunting, wasting and underweight it may be the reason community with lower socioeconomic status and less delivery of health services as these findings are in contrast with the studies of $[6,27,78]$. Family size significantly associated with malnutrition status of wasting, stunting and underweight as family size increases malnutrition status wasting, stunting and underweight increases, reason underlying is this with family increase resources become scare and less nutrition and care focused to children. These findings are consistent with studies of $[10,16,22$, $78]$ and in contrast the studies of [11, 42]. Urban areas children indicated a reduced frequency to be stunted rather than rural area the reason of more appropriate nutrition and access of health services and these findings are supported in the study [22]. In developing countries, children from rural area consider more vulnerable to malnourishment due to differences of limited economic resources, inadequate education access and poor availability of poor health facilities as these findings supported by the studies of [24, 74]. Mother education has significant relation with reducing stunting; increasing mother education reduces stunting status of children because the educated mothers have more knowledge related to child health, nutrition and usage of health services [41]. These findings are alike with the studies of $[18,26,34$, 50, 69]. Children of lowest wealth quintile were higher frequency of malnutrition (stunting, wasting and underweight) rather than higher wealth quintile family children due to underlying reason of less affordability of healthcare, quality nutrition and hygiene rather than rich families. These results are similar with the studies of $[25,79]$. Households with food shortage were higher prevalence of malnutrition (stunting, wasting and underweight) in children rather than children adequate access of food. Adequate nutrition promotes health and resistance against diseases, while inadequate nutrition causes to increase severity of stunting, wasting and underweight. These findings are consistent with the study of [63]. Children with incomplete immunization status were found more prevalence of malnutrition compared to those children with completed immunization. Incomplete immunization increases risk of diseases among children [26]. These findings are consistent with the studies of $[26,48,49,60$, $62]$. Household access of treated water their children was $47-70 \%$ less chance of stunting and underweight rather than children not access of treated water, and findings are alike the study of [79]. Households access of sanitation facility their children were $80 \%$ less prevalence of stunting compared to those children having of access of sanitation facility as findings are similar the studies of $[62$, 79].

\section{Conclusion}

Results of the study indicated higher frequency of malnutrition risk that causing foremost health problem among children aged under five in district Multan of Punjab province, Pakistan. This study identified gender, age, area, level of maternal education, family income, family size, sufficient food access and completed immunization are derived factors and significantly associated with childhood malnutrition. Male children have more threat of malnutrition rather than female children need to appropriately focus male child nutrition needs to reducing vulnerability of malnutrition. In overcoming the malnutrition issue, there is need to promote awareness about education and trainings specifically in rural areas about food nutritional value, diseases of nutritional deficiency, significance of personal hygiene, value of maternal education, use of treated water and sanitation facility. Mutual cooperation among government, Non-Governmental Organizations (NGOs) and community is prerequisite for developing and implementing strategies and policy measures of nutrition and awareness campaigns for improving child health. Health extension institutions need to use print media, social media and electronic media as significant sources for promoting the nutrition education awareness of malnutrition among children and its protective measures. Improving nutritional status of child, there is need of proper intervention through promoting the programs of children vaccination for competing immunization and adequate nutrition for children as increasing resistant to diseases and enhancing physical strength.

\section{Acknowledgements \\ Not applied. \\ Authors' contributions \\ Dilshad Ahmad developed idea, wrote the manuscript and estimated the data, Aisha Imtiaz compiled data, while Muhammad Afzal finally reviewed it.}

Funding

The study has no funding source from any institution or donor agency.

Availability of data and materials

This study used secondary source data from Multiple Indicator Cluster Survey (MICS) 2018 Bureau of Statistics Punjab, Pakistan.

Competing interests

Authors have no competing interests

\section{Author details}

${ }^{1}$ Department of Management Sciences, COMSATS University Islamabad, Vehari Campus, Islamabad, Pakistan. ${ }^{2}$ Department of Economics, Preston University, Islamabad, Islamabad, Pakistan. 
Received: 15 July 2019 Accepted: 13 August 2020

Published: 30 August 2020

\section{References}

1. Abuya BA, Ciera J, Kimani-Murage E (2012) Effect of mother's education on child's nutritional status in the slums of Nairobi. BMC Pediatr 12(1):80

2. Achakzai P, Khan R (2016) Nutritional status and associated factors among children less than five years of age in tehsil Zarghoon town, District Quetta, Baluchistan. J Ayub Med Coll Abbottabad 28(1):146-151

3. Afridi MF, Khushdil A, Riaz S, Ehsan A (2014) Nutritional status of preschool children - a cross-sectional study in Mingora. Swat J Postgrad Med Inst 2014(28):314-328

4. Agho KE, Inder KJ, Bowe SJ, Jacobs J, Dibley MJ (2009) Prevalence and risk factors for stunting and severe stunting among under-fives in North Maluku province of Indonesia. BMC Pediatr 9(1):64

5. Ali W, Ayub A, Hussain H (2015) Prevalence and associated risk factors of under nutrition among children aged 6 to 59 months in internally displaced persons of jalozai camp, District Nowshera, Khyber Pakhtunkhwa. J Ayub Med Coll Abbottabad 27(3):556-559

6. Alom J, Islam MA, Quddus M (2009) Socioeconomic factors influencing nutritional status of under-five children of Agrarian families in Bangladesh: a multilevel analysis. Bangladesh J Agric Econ 32(4):63

7. Anwar HN, Zafar MI, Hussain S (2006) Health screening of primary school children-a case study of district Sargodha-Pakistan. Pak J Life Soc Sci 4:40-47

8. Anwer I, Awan JA (2003) Nutritional status comparison of rural with urban school children in Faisalabad District, Pakistan

9. Asim M, Nawaz Y (2018) Child malnutrition in Pakistan: evidence from literature. Children 5(5):60

10. Babar NF, Muzaffar R, Khan MA, Imdad S (2010) Impact of socioeconomic factors on nutritional status in primary school children. J Ayub Med Coll Abbottabad 22(4):15-18

11. Babatunde RO, Olagunju FI, Fakayode SB, Sola-Ojo FE (2011) Prevalence and determinants of malnutrition among under-five children of farming households in Kwara State, Nigeria. J Agric Sci 3(3):173

12. Baig-Ansari N, Rahbar MH, Bhutta ZA, Badruddin SH (2006) Child's gender and household food insecurity are associated with stunting among young Pakistani children residing in urban squatter settlements. Food Nutr Bull 27(2):114-127

13. Batool SAIMA, Shaheen ANEELA, Rehman RABEYA, Qamar S, Ahsan Raza SM, Jabeen R, Nisa F (2012) To assess the nutritional status of primary school children in an Urban school of Faisalabad. Pak J Med Health Sci A 4:160

14. Becker GS (1965) A theory of the allocation of time. Econ J 75:493-517

15. Behrman JR, Deolalikar AB (1989) Agricultural wages in India: the role of health, nutrition, and seasonality. In Seasonal Variability in Third World Agriculture: The Consequences for Food Security, pp. 107-117 [DE Sahn, editor]. Baltimore, MD: Johns Hopkins University Press

16. Beyene TT (2012) Predictors of nutritional status of children visiting health facilities in Jimma Zone, South West Ethiopia. Int J Adv Nurs Sci Pract $1(1): 1-13$

17. Currie C, Hurrlemann K, Settertobulte W, Smith R, Todd J (2000) Health and health behaviour among young people: international report (No. EUR/ICP/IVST 060305 (A)). Copenhagen: WHO Regional Office for Europe

18. Das S, Gulshan J (2017) Different forms of malnutrition among under five children in Bangladesh: a cross sectional study on prevalence and determinants. BMC Nutr 3(1):1

19. Demissie S, Worku A (2013) Magnitude and factors associated with malnutrition in children 6-59 months of age in pastoral community of Dollo Ado district, Somali region, Ethiopia. Sci J Public Health 1(4):175-183

20. Emamian MH, Gorgani N, Fateh M (2011) Malnutrition status in children of Shahroud. Iran 6(1):7-14

21. Farid-ul-Hasnain S, Sophie R (2010) Prevalence and risk factors for Stunting among children under 5 years: a community based study from Jhangara town, Dadu Sindh. J Pak Med Assoc 60(1):41-44

22. Fentaw R, Bogale A, Abebaw D (2013) Prevalence of child malnutrition in agro-pastoral households in Afar Regional State of Ethiopia. Nutr Res Pract 7(2):122-131
23. Food and Agriculture Organization (2019) Global Report on Food Crisis 2019, Food and Agriculture Organization United Nations. http://www. fao.org/resilience/resources/resources-detail/en/c/1187704/

24. Fotso JC (2007) Urban-rural differentials in child malnutrition: trends and socioeconomic correlates in sub-Saharan Africa. Health Place 13(1):205-223

25. Garcia S, Sarmiento OL, Forde I, Velasco T (2013) Socio-economic inequalities in malnutrition among children and adolescents in Colombia: the role of individual-, household-and community-level characteristics. Public health Nutr 16(9):1703-1718

26. Gebre A, Reddy PS, Mulugeta A, Sedik Y, Kahssay M (2019) Prevalence of malnutrition and associated factors among under-five children in pastoral communities of afar regional state, Northeast Ethiopia: A community-based cross-sectional study. J Nutr Metabolism 2019:9187609. https://doi.org/10.1155/2019/9187609

27. Glover-Amengor M, Agbemafle I, Hagan LL, Mboom FP, Gamor G, Larbi A, Hoeschle-Zeledon I (2016) Nutritional status of children 0-59 months in selected intervention communities in northern Ghana from the africa RISING project in 2012. Arch Public Health 74(1):12

28. Government of Pakistan (GOP) (2018). 6th Population and Housing Census, 2017, Pakistan Bureau of Statistics Ministry of Finance Islamabad, Government of Pakistan. http://www.pbs.gov.pk/content/provi sional-summary-results-6th-population-and-housing-census-2017-0

29. Government of Pakistan (GOP) (2019) Economic Survey of Pakistan, 2018-2019. Ministry of Finance Islamabad, Government of Pakistan, Islamabad

30. Government of Punjab (2018) Punjab Development Statistics, 2018, Planning and Development department Bureau of Statistics Government of the Punjab, Pakistan. http://www.bos.gop.pk/system/files/ Punjab\%20Development\%20Statistics\%202018.pdf

31. Government of Punjab (2019) Multiple Cluster Indicator Survey (MICS), 2018. Bureau of statistics Government of the Punjab, Pakistan. http:// www.bos.gop.pk/MultiplelndicatorClusterSurvey2017\#overlay-conte $\mathrm{xt}=$

32. Grossman M (1982) The demand for health after a decade. J Health Econ 1(1):1-3

33. Gul R, Kibria Z (2013) Prevalence and predeterminants of malnutrition in children under 3 years of age in the two rural communities of peshawar. Khyber Med Univ J 5(4):190-4

34. Habyarimana F (2016) Key determinants of malnutrition of children under five years of age in Rwanda: simultaneous measurement of three anthropometric indices. Afr Popul Stud 30(2):2328-2340

35. Hilbe JM (2011) Logistic regression. Int Encycl Stat Sci 2011:755-758

36. Hosmer DW, Lemeshow S (2000) Applied logistic regression. Wiley, New York

37. http://www.unicef.org/sowc98/

38. John R (1971) A theory of justice. Oxford University Press, Oxford

39. Johnson RA, Wichern DW (1998) Principal components. Appl Multivar Stat Anal 6:430-481

40. Jones $G$ (2005) Multinationals and global capitalism: From the nineteenth to the twenty first century. Oxford University Press on Demand, Oxford

41. Kavosi E, Rostami ZH, Kavosi Z, Nasihatkon A, Moghadami M, Heidari M (2014) Prevalence and determinants of under-nutrition among children under six: a cross-sectional survey in Fars province

42. Khan GN, Turab A, Khan MI, Rizvi A, Shaheen F, Ullah A et al (2016) Prevalence and associated factors of malnutrition among children under-five years in Sindh, Pakistan: a cross-sectional study. BMC Nutr 2(1):69

43. Khan T, Khan REA, Raza MA (2015) Gender analysis of malnutrition: a case study of school-going children in Bahawalpur. Asian Dev Policy Rev 3(2):29-48

44. KhanKhattak MMA, Shah JSA (2010) Malnutrition and associated risk factors in pre-school children (2-5 years) in district Swabi (NWFP)-Pakistan. J Med Sci 10(2):34-39

45. Khuwaja S, Selwyn BJ, Shah SM (2005) Prevalence and correlates of stunting among primary school children in rural areas of southern Pakistan. J Trop Pediatr 51(2):72-77

46. Kikafunda JK, Walker AF, Collett D, Tumwine JK (1998) Risk factors for early childhood malnutrition in Uganda. Pediatrics 102(4):e45-e45 
47. Laghari ZA, Soomro AM, Tunio SA, Lashari K, Baloach F G, Baig NM, Bano S (2015) Malnutrition among children under five years in district Sanghar, Sindh, Pakistan. Gomal J Med Sci 13(1)

48. Lima MDC, Motta MEFA, Santos EC, Silva GAPD (2004) Determinants of impaired growth among hospitalized children: a case-control study. São Paulo Med J 122(3):117-123

49. Ma'alin A, Birhanu D, Melaku S, Tolossa D, Mohammed Y, Gebremicheal K (2016) Magnitude and factors associated with malnutrition in children 6-59 months of age in Shinille Woreda, Ethiopian Somali regional state: a cross-sectional study. BMC Nutr 2(1):44

50. Mahmood S, Nadeem S, Saif T, Mannan M, Arshad U (2016) Nutritional status and associated factors in under-five children of Rawalpindi. J Ayub Med Coll Abbottabad 28(1):67-71

51. Meshram II, Arlappa N, Balakrishna N, Rao KM, Laxmaiah A, Brahmam GNV (2012) Trends in the prevalence of undernutrition, nutrient \& food intake and predictors of undernutrition among under five year tribal children in India. Asia Pac J Clin Nutr 21(4):568-576

52. Mian RM, Ali M, Ferroni PA, Underwood P (2002) The nutritional status of school-aged children in an urban squatter settlement in Pakistan. Pak J Nutr 1(3):121-123

53. Mohsena M, Mascie-Taylor CN, Goto R (2010) Association between socio-economic status and childhood undernutrition in Bangladesh; a comparison of possession score and poverty index. Public health Nutr 13(10):1498-1504

54. Mohseni M, Aryankhesal A, Kalantari N (2017) Factors associated with malnutrition among under five-year-old children in Iran: a systematic review. Ann Trop Med Public Health 10(5):1147

55. Mosiur, R., Golam, M., \& Nasrin, S. O. (2009). Nutritional status among children aged 24-59 months in rural Bangladesh: an assessment measured by BMI index. Internet J Biol Anthropol 3(1)

56. Mushtaq MU, Gull S, Khurshid U, Shahid U, Shad MA, Siddiqui AM (2011) Prevalence and socio-demographic correlates of stunting and thinness among Pakistani primary school children. BMC Public Health 11(1):790

57. Mushtaq MU, Gull S, Mushtaq K, Abdullah HM, Khurshid U, Shahid U et al (2012) Height, weight and BMl percentiles and nutritional status relative to the international growth references among Pakistani school-aged children. BMC Pediatr 12(1):31

58. Nisar YB, Aurangzeb B, Hazir T (2013) Nutritional status of hospitalized children with nutritional anaemia: a cross sectional study. Ann Pak Inst Med Sci 9(3):122-125

59. Nuruddin R, Lim MK, Hadden WC, Azam I (2009) Comparison of estimates of under-nutrition for pre-school rural Pakistani children based on the WHO standard and the National Center for Health Statistics (NCHS) reference. Public health Nutr 12(5):716-722

60. Nzala SH, Siziya S, Babaniyi O, Songolo P, Muula AS, Rudatsikira E (2011) Demographic, cultural and environmental factors associated with frequency and severity of malnutrition among Zambian children less than five years of age. J Public Health Epidemiol 3(8):362-370

61. Osmani SR (ed) (1992) Nutrition and poverty. Oxford University Press, Oxford

62. Owoaje E, Onifade O, Desmennu A (2014) Family and socioeconomic risk factors for undernutrition among children aged 6 to 23 Months in Ibadan, Nigeria. Pan Afr Med J 17

63. Piniel A (2016) Factors contributing to severe acute malnutrition among the under five children in Francistown-Botswana (Doctoral dissertation, University of the Western Cape)

64. Rao S (2001) Nutritional status of the Indian population. J Biosci 26(4):481-489

65. Rehman Z, Ishtiaq M, Naeem M, Gul R, Amjad M, Iftikhar B (2013) Prevalence of malnutrition among school going children of university campus peshawar; Saidu Medical College: Swat, Pakistan, 2013; Available online: http://www.smcswat.edu.pk/Vol-4-No-1/Dr\%20Zai\%20ur\%20rehman. doc. Accessed on 25 December 2017

66. Riaz R, Sultana A, Hameed S, Tehseen I, Sabir SA (2010) Nutritional status of school going children. J Rawalpindi Med Coll 14:51-54

67. Seckler D (1982) Small but healthy: a basic hypothesis in the theory, measurement and policy of malnutrition. Newer Conc Nutr Implic Policy 30(10):127-137
68. Shah SM, Selwyn BJ, Luby S, Merchant A, Bano R (2003) Prevalence and correlates of stunting among children in rural Pakistan. Pediatr Int 45(1):49-53

69. Sharifzadeh G, Mehrjoofard H, Raghebi S (2010) Prevalence of malnutrition in under 6-year olds in South Khorasan, Iran. Iran J Pediatr 20(4):435

70. Silveira KB, Alves JF, Ferreira HS, Sawaya AL, Florêncio TM (2010) Association between malnutrition in children living in favelas, maternal nutritional status, and environmental factors. J Pediatr 86(3):215-220

71. Singh H, Chaudhary V, Joshi HS, Upadhyay D, Singh A, Katyal R (2016) Socio-demographic correlates of nutritional status of under-five children. Muller J Med Sci Res 7:44-49

72. SMART Survey Report (2016) District Umerkot, Sindh, Pakistan. Available online: http://reliefweb.int/report/pakistan/smart-survey-report-taluk a-district-umerkot-sindh-pakistan-january-2016. Accessed on 31 Jan 2016

73. Smith LC, Haddad $L$ (2000) Explaining child malnutrition in developing countries: a cross-country analysis(vol 111). Intl Food Policy Res Inst

74. Srinivasan CS, Zanello G, Shankar B (2013) Rural-urban disparities in child nutrition in Bangladesh and Nepal. BMC Public Health 13(1):581

75. State Bank of Pakistan (2019) State Bank of Pakistan various publications 2019, Government of Pakistan

76. Strauss J, Thomas D (1995) Human resources: empirical modeling of household and family decisions. Handb Dev Econ 3:1883-2023

77. Svedberg P (2000) Poverty and undernutrition: theory, measurement, and policy. Clarendon Press, Oxford

78. Tadesse A, Hailu D, Bosha T (2017) Nutritional status and associated factors among pastoralist children aged 6-23 months in Benna Tsemay Woreda, South Omo Zone, Southern Ethiopia. Int J Nutr Food Sci 7(1):11

79. Tadesse A, Hailu D, Bosha T (2018) Nutritional status and associated factors among pastoralist children aged 6-23 months in Benna Tsemay Woreda, South Omo zone, Southern Ethiopia. Int J Nutr Food Sci 7(1):11-23

80. Teferi MB, Hassen HY, Kebede A, Adugnaw E, Gebrekrstos G, Guesh M (2016) Prevalence of stunting and associated factors among children aged 06-59 months in Southwest Ethiopia: a cross-sectional study. J Nutr Health Food Sci 2016:1-6

81. Ullah H, Ullah B, Karim S, Tariq I, Khan AK, Mir S et al (2014) Malnutrition amongst under-five years children in Swat, Pakistan: prevalence and Risk Factors. Trop J Pharm Res 13(8):1367-1370

82. UNICEF (2018) National Nutritional Survey Key Findings Report, 2018. United Nations International Children Emergency Funds New York. https ://www.unicef.org/pakistan/reports/national-nutrition-survey-2018-keyfindings-report

83. UNICEF (2019) Country wise over review Malnutrition burden in Pakistan, United Nations International Children Emergency Fund, New York, USA. https://globalnutritionreport.org/media/profiles/v1.9.7/pdfs/pakistan.pdf

84. UNICEF (1998) Malnutrition: causes, consequences and solution. The state of the world's children Available at: https://www.unicef.org/sowc/ archive/ENGLISH/The\%20State\%20of\%20the\%20World\%275\%20Children \%201998.pdf

85. United Nations (2016) Sustainable development goals report. Retrieved from https://www.unep.org/environmentunderreview/sites/unep.org. environmentunderreview/files/documents/The\%20Sustainable\%20Dev elopment\%20Goals\%20Report\%202016 0.pdf

86. Vella V, Tomkins A, Borghesi A, Migliori GB, Adriko BC, Crevatin E (1992) Determinants of child nutrition and mortality in north-west Uganda. Bull World Health Organ 70(5):637

87. Victora CG, De Onis M, Hallal PC, Blössner M, Shrimpton R (2010) Worldwide timing of growth faltering: revisiting implications for interventions. Pediatrics 125(3):e473-e480

88. World Bank Group (2019) Levels and Trends in Child Malnutrition Key Findings Edition, 2019. World Bank Group, United Nations, New York. https://www.who.int/nutgrowthdb/jme-2019-key-findings.pdf?ua=1

89. World Health Organization (2017) Levels and trends in child malnutrition UNICEF - WHO - World Bank Group joint child malnutrition estimates, Key findings of the 2017 edition. https://www.who.int/nutrition/publi cations/jointchildmalnutrition_2017 estimates/en/

90. World Health Organization (2019) Levels and trends in child malnutrition key findings edition, 2019. World Health Organization (WHO). United 
Nations New York. https://www.who.int/nutgrowthdb/jme-2019-keyfindings.pdf?ua $=1$

91. World Health Organization (2018) World Health Statistics 2018, Monitoring Health for Sustainable Development Goals $\left(\mathrm{SDG}_{\mathrm{s}}\right)$, World Health Organization. https://apps.who.int/iris/bitstream/handle/10665/27259 6/9789241565585-eng.pdf?ua $=1$

92. Wu L, Yang Z, Yin SA, Zhu M, Gao H (2015) The relationship between socioeconomic development and malnutrition in children younger than 5 years in China during the period 1990 to 2010. Asia Pac J Clin Nutr 24(4):665
93. Zainab S, Kadir MM (2016) Nutritional status and physical abuse among the children involved in domestic labour in Karachi Pakistan: a crosssectional survey. J Pak Med Assoc 66(10):1243

\section{Publisher's Note}

Springer Nature remains neutral with regard to jurisdictional claims in published maps and institutional affiliations.

\section{Submit your manuscript to a SpringerOpen ${ }^{\circ}$ journal and benefit from:}

- Convenient online submission

- Rigorous peer review

- Open access: articles freely available online

- High visibility within the field

- Retaining the copyright to your article

Submit your next manuscript at $\boldsymbol{\nabla}$ springeropen.com 